\title{
EDITORIAL
}

\section{Materials for Healthcare Applications Symposium, EUROMAT 2011 (Montpellier, France, 12-15 September 2011)}

\author{
Aldo R Boccaccini \\ University of \\ Erlangen-Nuremberg, \\ Germany
}

\section{João F Mano}

University of Minho, Portugal

\section{Aranzazu del Campo \\ Max Planck Institute for \\ Polymer Research, Mainz, \\ Germany}

Enrica Verné

Politecnico di Torino, Italy
The advancement of the healthcare and biomedical sectors requires the improvement of traditional biomaterials and the development of new and multifunctional biomaterial combinations with enhanced structural and biological performance. The need for biomaterials to help tackle the health problems of an increasing elderly population is continuously growing. Biomaterials science and technology is highly interdisciplinary, which involves not only the established materials science disciplines but also scientific fields such as chemistry, biology, bioengineering and medicine. The increasing impact of nanotechnology in the medical field must also be noted as this implies the development of biomimetic surfaces, nanostructured biomaterials and miniaturized devices.

At the last European Congress and Exhibition on Advanced Materials and Processes (EUROMAT 2011: http://euromat2011.fems.eu) held in Montpellier, France in September of last year, the topic of materials for healthcare was covered in three focused symposia, namely: i) bioactive coatings and material-tissue interfaces, ii) smart and biomimetic materials for biomedical applications and tissue engineering and iii) mechanical characterization and modeling of tissues and biomedical materials at all length scales. The oral and poster presentations reflected novel research on biomaterials covering new areas of processing, properties and applications of materials in the biomedical field. A broad variety of topics were presented, ranging from biomaterials for bone replacement, bioactive surfaces and coatings, nanocomposites and tissue engineering scaffolds, bioinspired biocomposites and antibacterial coatings.

The eight papers [1-8] published in this special issue of Biomedical Materials were selected from contributions presented at EUROMAT 2011 in the Materials for Healthcare Symposia, specifically for their focus in biomaterials for tissue engineering. It is recognized that successful biomaterials and structures for tissue engineering are those that closely mimic the composition chemistry and hierarchical structure of the native tissues to be replaced and regenerated, including the possibility of adaptation to the biological changes during the healing process, and which exhibit specific mechanical and biological functions to enable rapid new tissue regeneration. The papers selected for this special section went through the normal peer-review process of the journal and cover numerous novel biomedical materials, including a range of inorganic and functionalised bioactive coatings for prosthetic and bone regeneration applications, a series of advanced biodegradable polymer-inorganic composites for tissue engineering and engineered nanocarriers for gene delivery also discussing the interaction of scaffolds with different stem cells.

As guest editors of this special section in Biomedical Materials, we are grateful to all authors and reviewers, who have supported this publication with their efforts and hard work, contributing to its timely publication. 


\section{References}

[1] Demnati I, Grossin D, Combes C, Parco M, Braceras I and Rey C 2012 Biomed. Mater. 7054101

[2] Ferraris S, Pan G, Cassinelli C, Mazzucco L, Verné E and Spriano S 2012 Biomed. Mater. 7054102

[3] Hild N, Fuhrer R, Mohn D, Bubenhofer S B, Grass R N, Luechinger N A, Feldman K, Dora C and Stark W J 2012 Biomed. Mater. 7054103

[4] Luz G M and Mano J F 2012 Biomed. Mater. 7054104

[5] García-García J M, Garrido L, Quijada-Garrido I, Kaschta J, Schubert D W and Boccaccini A R 2012 Biomed. Mater. 7054105

[6] Ojea-Jiménez I, Tort O, Lorenzo J and Puntes V F 2012 Biomed. Mater. 7054106

[7] Handel M, Hammer T R and Hoefer D 2012 Biomed. Mater. 7054107

[8] Pascaud P, Bareille R, Bourget C, Amédée J, Rey C and Sarda S 2012 Biomed. Mater. 7054108 